\title{
Laurence Guéllec, Tocqueville et les langages de la démocratie
}

\section{Lise Sabourin}

\section{Q OpenEdition}

10 Journals

\section{Édition électronique}

URL : http://journals.openedition.org/studifrancesi/30573

DOI : $10.4000 /$ studifrancesi.30573

ISSN : 2421-5856

\section{Éditeur}

Rosenberg \& Sellier

\section{Édition imprimée}

Date de publication : 1 avril 2006

Pagination : 180

ISSN : 0039-2944

\section{Référence électronique}

Lise Sabourin, «Laurence Guéllec, Tocqueville et les langages de la démocratie », Studi Francesi [En ligne], 148 (XLX|I) | 2006, mis en ligne le 30 novembre 2015, consulté le 19 avril 2021. URL : http:// journals.openedition.org/studifrancesi/30573; DOI : https://doi.org/10.4000/studifrancesi.30573

Ce document a été généré automatiquement le 19 avril 2021.

\section{(c) (i) $\odot$}

Studi Francesi è distribuita con Licenza Creative Commons Attribuzione - Non commerciale - Non opere derivate 4.0 Internazionale. 


\title{
Laurence Guéllec, Tocqueville et les langages de la démocratie
}

\author{
Lise Sabourin
}

\section{RÉFÉRENCE}

LAURENCE GUÉLlec, Tocqueville et les langages de la démocratie, Paris, Honoré Champion, 2004, pp. 445.

1 Cette thèse constitue assurément l'ouvrage de référence pour l'agrégation de lettres modernes 2005 qui, en mettant au programme le $2^{\mathrm{e}}$ tome de la Démocratie en Amérique, se heurte à un manque d'analyses littéraires de l'œuvre redécouverte par la sociologie, la philosophie politique et l'histoire. Laurence Guéllec a eu le mérite de concevoir les prémices de cette approche littéraire d'un auteur qui n'est pas assez étudié comme écrivain au sein de la génération romantique à laquelle il appartient tout en s'en détachant.

2 Le plan de l'ouvrage s'attache à déterminer les conditions d'un discours sur la démocratie à l'époque, à cerner par l'intertextualité et l'histoire le lien entre libéralisme et littérature jusqu'à Tocqueville, enfin sa pratique de l'état d'auteur conçue comme une médiation encore incertaine, mais vouée à se développer dans les sociétés modernes.

3 Tocqueville place son traité au sein d'une fabrique de parole politique; il construit un système hypothético-déductif qui refuse la confusion entre son contemporain et le démocratique. Il n'hésite pas à critiquer le romantisme (français comme allemand) dans son chapitre sur le panthéisme philosophique et poétique; il en possède pourtant le principe de transcendance, mais veut parler au peuple - nouveau souverain - sans tomber dans la voyance allégorique et mythificatrice d'un Hugo ou d'un Michelet. Il se révèle pourtant visionnaire dans son tableau de l'État tutélaire, mais l'imagination est pour lui un relais, une logique portée à l'extrême, jusqu'à un radicalisme théorique. 
4 Ainsi, dans le compagnonnage de Pascal, reprend-il la métaphore des ténèbres, celle de l'homme ange et démon; à La Bruyère ses éthopées, sous forme de saynètes sur les tribulations du citoyen moderne risquant de passer à côté du bonheur; à La Rochefoucauld, ses sentences morales et ses maximes sur l'homme; à Voltaire, le comique des idées, le plaisir de l'intelligence, sans exclure pour autant quelque mélancolie de la raison, convaincu qu'anecdotes, croquis, vignettes et caricatures ne peuvent forger l'impossible roman de la démocratie. Il renonce à la rhétorique du sublime révolutionnaire au nom de la réserve politique et préfère se faire sociologue des temps nouveaux à « l'épreuve du risque ».

5 Sa quête obsessionnelle de la clarté dans l'héritage du classicisme, mais aussi par refus de certaines obscurités romantiques, est marquée par une recherche de brièveté relevant du souci pédagogique, par la préoccupation d'une perspective scientifique sans tomber dans le positivisme, mais au nom du «protocole de l'esprit» (comme le disait Furet). Il s'emploie aux stratégies d'une rhétorique philosophique, soucieuse de régularité des formes et d'intelligibilité dans l'instabilité contemporaine: les métaphores du fleuve et du cercle, le goût du paradoxe s'entrelacent avec une ironie de distanciation, une attention au détail au sein même du tableau de pensée, propres à formuler l'énigme démocratique de l'histoire ouverte au peuple. Profondément liée au fond, la forme de sa langue veut se plier au "glissement de faire savoir ou faire croire " démocratique (p. 406): ni fétichisme des mots, ni scepticisme relativiste, car «l'histoire traverse et redéfinit » les concepts par l'empilement des sens en un va-et-vient évolutif qui explique le réformisme notionnel de ce modéré, élaborant, parfois par innovation et indéfinition, l'explicitation du savoir politique, avec indépendance et équilibre logique du discours au milieu même du désordre sémantique (ainsi L. Guéllec répondelle à ceux qui reprochent à Tocqueville de mal cerner le sens du mot "démocratie » que l'auteur se devait de le penser en termes de société, non plus seulement de politique comme les Anciens).

6 L. Guéllec est très efficace dans sa démonstration: Tocqueville veut éclairer le lecteur, citoyen et acteur politique, sans tomber dans le didactisme; il cherche à être «un moniteur et un publiciste, non un porte-parole» (p. 407), « un médiateur et un passeur, non un instructeur» (p. 408), un penseur conscient des limites de la culture politique de son siècle, voué à la démocratie, mais déstabilisé dans ses certitudes et encore incapable de plier la langue commune aux besoins de la modernité civique. Il tâche de se conformer aux attentes du public sans s'y confondre, avec une rigueur intellectuelle qui ne se laisse pas aller à la confusion abstractive d'une démocratie européenne naissante. 